\title{
THE EFFECT OF INPUT SPACING ON EFL LEARNERS' VOCABULARY KNOWLEDGE
}

\author{
Ashraf Bagherian Sararoodi, Mohammad Taghi Farvardin \\ Department of English Language Teaching, Ahvaz Branch, \\ Islamic Azad University, Ahvaz, Iran \\ E-mail: farvardin@iauahvaz.ac.ir
}

Received: 15 October 2020;

Accepted: 19 December 2020

\begin{abstract}
The lag or the intersession interval (ISI) is the gap between two learning sessions. Lag effects are one of those effects that few studies have examined. Moreover, albeit a huge bulk of research on input spacing (i.e., phenomenon of distributed learning conditions) has been done in laboratory setting, few studies have directly examined this issue within real contexts. Therefore, the purpose of this study was to examine the impact of not only spaced-short but also spaced-long condition on the vocabulary knowledge of EFL learners. To achieve this goal, 37 intermediate level EFL learners were selected from four intact classes. The whole process took place in nine weeks; two testing sessions for pretest and a 28-day delayed posttest, two learning sessions and a final review session. Learning was done in two sessions. In this process, 20 target items were divided into 10 target words from each two lists. The first 10 words were studied during the first session, and reviewed during the review session. Eight days (intersession interval) ISI was specified for the spaced-long condition. Finally, a 1-day ISI was specified for the spaced-short condition. To do so, the second 10 words during the second session were studied, and then they were reviewed during the review session. The results of paired samples t-test revealed that spaced-long input was more effective than the space-short. Spaced-long condition could help learners for conceptual understanding to develop, reduce forgetting and provide opportunities for learners to learn more efficiently.
\end{abstract}

Keywords: EFL learners; input spacing; vocabulary knowledge; spaced-long condition; spaced-short condition

\section{Introduction}

Vocabulary is considered as an indispensable component of language learning (Nation \& Webb, 2011). It is also believed that vocabulary learning is indisputably dependent upon constant encounters with the target words (Rohrer, 2015). Therefore, researchers have argued that the spacing between repetitions is of high importance in improving vocabulary retention (Goossens, Camp, Verkoeijen, \& Tabbers, 2016). The term spacing is the phenomenon of distributed learning conditions (Bui, Ahmadian, \& Hunter, 2019; Rogers, 2017). Moreover, the latest studies have illustrated the importance of intervals during studying which are separated in time in particular vocabulary learning (Namaziandost et al., 2020). Spacing is also believed to enhance memory during learning events compared to 
learning in one session that is easily forgotten (e.g. Cepeda et al., 2006). Contrary to massing or cramming, breaking down larger tasks into smaller ones is the most important influence and effect of spacing on learning (Cepeda et al., 2008).

The most common spacing effect is referred to the effective of lag and retention interval (RI). The retention interval is the period between a learner's exposure to information and being tested for retention of that information. During the retention interval, the learner maybe exposed to a distractor or other information (gap between the last learning session and the final test session). The lag or the intersession interval (ISI) is the period among the end of one academic session and the beginning of the next session (gap between two learning sessions) (Cepeda et al., 2006; Lotfolahi \& Salehi, 2017). Lag effects are one of those effects that few studies have investigated (Rogers, 2017; Rohrer, 2015).

Vocabulary knowledge is also categorized into two types, receptive and productive (Nation, 2001; Tahmasbi \& Farvardin, 2017). If you understand the meaning of a word when you hear or read it is part of your receptive vocabulary (Webb, 2005, 2008). On the other hand, when you are able to produce a word during listening or writing in a way that is appropriate is part of your productive vocabulary (Nation, 2001). In other words, receptive vocabulary knowledge is referred to the capability to comprehend a word when the learner hears or sees it, while productive knowledge refers to producing a word when learner can use it in his/her writing or speech (Laufer \& Goldstein, 2004). Regarding the abovementioned issues, this study aimed to examine the effect of spaced-long and spaced-short on the second language vocabulary knowledge.

\section{Literature Review}

The importance of distributed practice has been considered during studying about spacing ang lag effect. The more amount of study time, the more long last-lasting learning (Baleghizadeh \& Shafeie, 2019; Carpenter, 2017; Cepeda et al., 2006; Ullman \& Lovelett, 2018). However, the findings have had pedagogical implications for vocabulary teaching and learning (Goossens et al., 2016). Furthermore, according to some studies, superiority of distributed practice over massed practice is emphasized (Baleghizadeh \& Shafeie, 2019; Nakata, 2015).

It has been also reported that the positive effect of spacing on vocabulary learning and retention is more than cramming (Farvardin, 2019; Goossens et al., 2016; Sabel, Cepeda, \& Kapler, 2011). In an experimental study, Nakata (2015) focused on spacing effects (expanding and equal) on L2 vocabulary learning. Twenty English words were taught to 128 participants who were Japanese college students. In order to teach a series of words, two sets of ten items including six nouns and four verbs were set. The result showed the importance and significance of expanding spacing. In addition, it was concluded that the enhancing of vocabulary learning through expanding spacing.

Lotfolahi and Salehi (2017) later tried to explore the spacing effects in vocabulary learning. To this end, 28 seventh-grade students were selected. Ten words with different tenses were chosen to be taught. Then, students were randomly assigned to two groups, spaced and massed. The findings revealed that students who learned words in long space (long term retention of information) were more successful than massed group.

Rogers and Cheung (2018) investigated the effect of input spacing on EFL learners' vocabulary learning. In this study, three aspects of spacing effect were examined: input spacing, lag effect and vocabulary learning. The participants, who were 8 or 9 years old (study grade3), were chosen to learn twenty English adjectives. Multiple choice recognition 
was selected as a pre-test. Nine weeks plus two testing sessions were specified for the whole experiment. Twenty words were taught by dividing into two lists. The results revealed superiority of spaced-short condition over spaced-long condition. Therefore, it can be implied that shorter time between training and review is more beneficial for young learners in real classroom. It is believed the practical and effective way of learning vocabulary is through the distributed way rather than one single session (Küpper-Tetzel, 2014; Toppino \& Gerbier, 2014). Therefore, there indeed exists a strong relationship between spacing/lag effects and vocabulary learning. There are also more aspects of spacing and vocabulary learning to be investigated, especially in EFL contexts.

The present study used some methods to improve students' memory for reminding and using the words automatically. The target vocabulary was taught to participants by applying input spacing. Therefore, the effect of spaced-short and spaced-long conditions were examined in this context. Moreover, there is inadequate evidence about the effect of input spacing on vocabulary knowledge. Thus, in this study, it was aimed to bridge the existing gap by examining the effect of spaced-short and spaced-long input on the vocabulary knowledge of intermediate level EFL learners. To deal with the objective of this study, the following research question was raised:

Q: To what extent do spaced-short and spaced-long input affect intermediate level EFL learners' vocabulary knowledge?

\section{Research Method}

This study utilized a pretest-posttest design. The whole process took place in nine weeks; two testing sessions for pretest and a 28-day delayed posttest, two learning sessions and a final review session.

\subsection{Participants}

Initially, a total of 40 female EFL learners from four intact classes at Safir institute in Ahvaz, Iran, were selected. However, 3 of them did not participate in the post-test, leaving 37 students as the final sample. All participants had been studying English in a language Institute for eight semesters. The institute had already determined the participants' level of language proficiency as intermediate. The participants' age ranged from 18 to $26(M=22$. $50, S D=1.67)$. The classes were held three times a week for 75 minutes.

\subsection{Instruments and Materials}

Twenty English nouns were selected as the target items. All of these nouns were related to crime and criminals which the students were going to study in that semester. These nouns were chosen due to the students' needs. EFL learners would confront with the title of the lesson that was related to these words. However, the target words surely were not in their books. The target words were arson, genocide, manslaughter, forgery, mugger, assassination, corruption, bribe, abduction, pilferage, fraud, assault, embezzlement, blackmail, perjury, smuggler, treason, vandal, libel, and slander. The relevant images were provided during teaching the target words. A power point file including the photos, pronunciations, meanings, and examples of the target words was designed and sent to the teacher. This was done for two reasons: first, it caused motivation, enthusiasm and confidence for students to understand the meaning of each word better and made positive impact on individual learning. Second, showing images made learners not be reluctant for learning and eager to use the words towards their own personal growth. 
Two weeks before the treatment, the participants took a pretest. The test was taken from learners to make sure that the participants did not know the meaning of the words. It was truly the first time for the learners to see the target words. The posttest was taken 28 days after each review session. The participants were asked to complete 20 sentences in the delayed post-test. They should complete the sentences in 10 minutes. The first letter of the word was written and hyphens were arranged to the number of letters. The reliability coefficient of the test was measured as 0.82 through KR-21 test. The content validity was also determined by giving the test to three well-experienced teachers who held $\mathrm{PhD}$ in English language teaching. A sample sentence is presented below:

The cinema was burned out in north London last night. The police suspect a - - - -.

\subsection{Procedures}

Thirty-seven Iranian EFL learners from Safir institute in Ahvaz, Iran, were selected. The procedure was done according to Rogers and Cheung (2018). The whole process took place in nine weeks; two testing sessions for pretest and a 28-day delayed posttest, two learning sessions and a final review session. Learning was done in two sessions. In this process, 20 target items were divided into ten target words from each two lists. The first 10 words were studied during the first session, and reviewed during the review session. Eight days ISI was specified for the spaced-long condition. Finally, a 1-day ISI was specified for the spaced-short condition. To do so, the second 10 words during the second session were studied, and then they were reviewed during the review session. All 20 words were taught by the teacher with the same method. The first 10 selected words for spaced-long were arson, genocide, manslaughter, forgery, mugger, assassination, corruption, bribe, abduction, and pilferage. The second 10 selected words for spaced-short were fraud, assault, embezzlement, blackmail, perjury, smuggler, treason, vandal, libel, and slander.

Before the beginning of treatment, the reason of experiment and procedures were discussed and laid out to the teacher, then the specified sheets and relevant materials were given to the teacher to be used in class. Teacher was supposed to teach the first 10 words during 15 or 20 minutes during the first session of teaching words. The same procedure was done in the second session. Finally, 20 minutes of class time were allotted to review the total words.

In step one, the pictures were shown to the learners and they were asked whether each knew the meaning, then the word was shown; the picture was on the left side of the projector and the word with its meaning on the right. Then, the teachers pronounced each word in particular some words that seemed difficult for the learners to say. After that, the teacher read out Persian meaning when necessary. Next, the sample example was shown, and students were given their own examples.

In step two, definitions of the words written on some pieces of papers were given to the participants in order to write the definite words. After that, each student read out the definitions and others had to guess the word. Two sample sentences are presented below:

The illegal burning of a building or other property: the crime of setting fire to sth

The activity was done for two reasons: one reason was enabling students to check their understanding and learning, and the other reason was making a positive relationship between the students to help them learn and memorize the words better.

In the third step, a session after training, a paper that contained 10 sentences was given to the participants. They were asked to complete the sentences. The first letter of the word 
was written and hyphens were arranged to the number of letters. The paper was given to each learner. They should complete the sentences in 10 minutes. Participants compared their answers to their partners then checked with the teacher in order to make sure that their answers were right. A sample sentence is presented below:

He claimed he was a licensed psychologist, but he turned out to be a f- - - -

\subsection{Data Analysis}

Spaced-short and spaced-long learning conditions were used as the target items in this study. The gathered data were analyzed through using SPSS software, version 24 . First, Kolmogorov-Smirnov (K-S) test was used to check the quality of data normality. Second, descriptive statistics were calculated. Third, a paired samples $t$ test was run to measure the effects of the treatment on the students' vocabulary learning.

\section{Results and Discussion}

Before conducting any analyses on the post-test, the normality of the distributions was checked. The results of the K-S test showed that the distribution of scores was normal. Then, the descriptive statistics including mean and standard deviation of the two learning schedules was measured (see Table 1).

Table 1. Descriptive Statistics of the Post-test Scores

\begin{tabular}{llll}
\hline Tasks & $\mathrm{N}$ & Mean & Std. Deviation \\
\hline Spaced-short & 37 & 5.81 & 1.603 \\
Spaced-long & 37 & 7.05 & 1.325 \\
\hline
\end{tabular}

As Table 1 depicts, the participants' mean score on the spaced-short condition was 5.81 and on the spaced-long condition was 7.05. The means of the treatments are different and the spaced-long condition seems to be better than the spaced-short condition. In Table 2, paired samples $t$ test was run to show if there was any significant difference between the post-tests.

Table 2. Results of Paired-Samples T-tests

\begin{tabular}{|c|c|c|c|c|c|c|}
\hline \multicolumn{7}{|c|}{ Paired Samples t-test } \\
\hline & \multicolumn{3}{|c|}{ Paired differences } & \multirow[t]{2}{*}{$\mathrm{t}$} & \multirow[t]{2}{*}{$\mathrm{df}$} & \multirow[t]{2}{*}{ Sig. } \\
\hline & Mean & SD & SEM & & & \\
\hline $\begin{array}{l}\text { Spaced-long- } \\
\text { Spaced-short }\end{array}$ & 1.24 & 1.458 & .205 & 11.58 & 36 & .000 \\
\hline
\end{tabular}

As Table 2 displays, a statistically significant difference between the performance of the groups on the post-test was observed since the $p$ value is lower than 0.05 . In fact, the participants learned the words in the spaced-long condition better than the spaced-short condition on the post-test.

Based on the results and statistics derived from different tests, the superiority of the result of spaced-long treatment ( 8 days ISI) showed better effect on the EFL learners' vocabulary knowledge than the spaced-short treatment (1day ISI specified). Although Rogers 
The Effect of Input Spacing on EFL Learners' Vocabulary Knowledge, Ashraf Bagherian Sararoodi, Mohammad Taghi Farvardin

and Chaung (2018) found that spaced-short led to better retention, the findings here suggest the superiority of spaced-long condition in learning vocabulary. In this regard, the optimum spacing capacity can be at variance across learners' motivation, group members, and acquiring skill settings (Rogers, 2017). The learners were eager to learn the first 10 words in long spacing. Despite teaching in every class, each participant had more time to review the first 10 words. According to the literature, in case that spacing benefits learning, the superiority of long spacing for learning has been emphasized over short spacing. Other studies have also confirmed the predominance of longer spacing for memory maintenance than short (e.g., Chaung, 2018; Rogers, 2017).

Taken together, the findings in vocabulary learning suggest that instruction from spaced-long condition was significantly better than spaced-short condition. One of the main reasons is participants' needs because of the lack of words in the participants' text book (Touchstone 3), the learners were eager to learn the words related to their lesson topics and they were all interested in learning the first 10 words in long spacing. On the other hand, the longer the distance, the better the learning (Namaziandost et al., 2020).

Despite teaching in every class, each participant had more time to review the first 10 words. According to some studies, in case that spacing benefits learning, longer spacing gaps are more beneficial for retention than short spacing (Goossens et al., 2016). According to Sobel et al. (2011), the advantage of vocabulary learning and retention from spacing is more practical and effective than cramming. Furthermore, the reason of this difference between the results of this study with some other studies can be related to the participants' proficiency level.

Furthermore, the results displayed that re-study activity was more effective after a delay. The positive effects of spacing in vocabulary learning are boundless for the reason that learners could learn, retain vocabulary items better and easy to access in future. Spaced-long condition could help learners for conceptual understanding to develop, reduce forgetting and provide opportunities for learners to learn more efficiently. Serrano and Huang (2018) believe that distributing words across learning sessions is better than massing them into one learning session when learners are learning vocabulary. The way that spacedshort was less effective than spaced-long cannot be explained by repetition effects. In this study, learning vocabulary might be better for longer-term retention.

\section{Conclusion}

The present study was undertaken to find out the effect of spacing on second language learning vocabulary by intermediate EFL learners. The results of this study showed that the longer the spacing in learning vocabulary, the better the retention and remembering the words. Therefore, the findings, in general, seem convincing enough to claim that lag effects would be better and learning could be facilitated when learners were in a real situation. The results of the present study are by no means complete. However, more research should be done for the way that authentic education environment could be facilitated through teaching and learning.

Since the impact of spacing in particular long spacing could help learners learn vocabulary, strategies can be trained to use strategically to learn how and when use these strategies. Thus, English teachers should know that teaching vocabulary in a legitimate context help learners improve their learning. They can also be trained to pay special attention to distributed learning conditions instead of just relying on rote memorization that leads to a superficial grasp of material that is quickly be forgotten. Therefore, input spacing 
and lag effects have finished up focal points of appropriated practice, with longer holes between instructional courses bringing about more prominent long haul maintenance of educational that is the point at which different learning scenes are spread over a more extended timeframe, bringing about better learning and maintenance (Cepeda et al., 2006; Rohrer, 2015).

There are some limitations in this investigation: First, the participants were EFL learners, and the context was not authentic. Second, if the participant size could be larger, the results would be more reliable. Finally, another limitation was time. The results could be different if it was conducted during a longer period.

\section{References}

Baleghizadeh, S., \& Shafeie, S. (2019). The effect of teaching formulaic sequences through spaced and non-spaced retrievals on Iranian EFL learners' oral fluency. Journal of English Language Teaching and Learning, 11(24), 79-114.

Bui, G., Ahmadian, M. J., \& Hunter, A. M. (2019). Spacing effects on repeated L2 task performance. System, 81, 1-13. doi: 10.1016/j.system.2018.12.006

Carpenter, S. (2017). Spacing effects on learning and memory. In Wixted J. T. (Ed.), Cognitive psychology of memory: A comprehensive reference (pp. 465-485). 2nd edition. Oxford: Academic Press.

Carpenter, S., Cepeda, N., Rohrer, D., \& Pashler, H. (2007). Enhancing learning and retarding forgetting: Choices and consequences. Psychonomic Bulletin \& Review, 14(2), $187-$ 193. doi.: 10.3758/BF03194050

Cepeda, N. J., Pashler, H., Vul, E., Wixted, J. T., \& Rohrer, D. (2006). Distributed practice in verbal recall tasks: A review and quantitative synthesis. Psychological Bulletin, 132, 354-380.

Cepeda, N. J., Vul, E., Rohrer, D., Wixted, J. T., \& Pashler, H. (2008). Spacing effects in learning: A temporal guideline of optimal retention. Psychological Science, 19(11), 1095-1102. doi: 10.1111/j.1467-9280.2008.02209.x

Farvardin, M. T. (2019). Effects of spacing techniques on EFL learners' recognition and production of lexical collocations. Indonesian Journal of Applied Linguistics, 9(2), 395403.

Goossens, N. A., Camp, G., \& Verkoeijen, P. P. (2016). Distributed practice and retrieval Practice in primary school vocabulary learning: A multi-classroom study. Applied Cognitive Psychology, 30(5), 700-712. DOI: 10.1002/acp.3245

Huang, Y., Liu, D., Tsai, T., \& Pan, Y. (2016). Effects of expanded vocabulary support on L2 listening comprehension. Language Teaching Research, 1-19. DOI: $10.1177 / 1362168816668895$

Küpper-Tetzel, C. E., Erdfelder, E., \& Dickhäuser, O. (2014). The lag effect in secondary school classrooms: Enhancing students' memory for vocabulary. Instructional Science, 42(3), 373-388. DOI: 10.1007/s11251-013-9285-2

Laufer, B., \& Goldstein, Z. (2004). Testing vocabulary knowledge: Size, strength, and computer adaptiveness. Language learning, 54(3), 399-436. DOI: 10.1111/j.00238333.2004.00260.x

Lotfolahi, A. R., \& Salehi, H. (2017). Spacing effects in vocabulary learning: Young EFL learners in focus. Cogent Education, 4, 1-10. DOI: 10.1080/2331186X.2017.1287391 
The Effect of Input Spacing on EFL Learners' Vocabulary Knowledge, Ashraf Bagherian Sararoodi, Mohammad Taghi Farvardin

Nakata, T. (2015). Effects of expanding and equal spacing on second language vocabulary learning: Does gradually increasing spacing increase vocabulary learning? Studies in Second Language Acquisition, 37(4), 677-711. DOI: 10.1017/S0272263114000825

Namaziandost, E., Sawalmeh, M. H. M., \& Soltanabadi, M. I. (2020). The effects of spaced versus massed distribution instruction on EFL learners' vocabulary recall and retention. Cogent Education, 7(1).

Nation, I. S. P. (2001). Learning vocabulary in another language. Cambridge, UK: Cambridge University Press.

Nation, I. S. P., \& Webb, S. (2011). Researching and analyzing vocabulary. Boston, MA: Heinle Cengage Learning.

Rogers, J. (2017). The spacing effect and its relevance to second language acquisition. Applied Linguistics, 38(6), 906-911. DOI: 10.1093/applin/amw052

Rogers, J., \& Cheung, A. (2018). Input spacing and the learning of L2 vocabulary in a classroom context. Language Teaching Research, 1-26. DOI: $10.1177 / 1362168818805251$

Rohrer, D. (2015). Student instruction should be distributed over long time periods. Educational Psychology Review, 27, 635-643. DOI: 10.1007/s10648-015-9332-4

Rohrer, D., \& Pashler, H. (2007). Increasing retention without increasing study time. Current Directions in Psychological Science, 16(4), 183-186. DOI: 10.1111/j.14678721.2007.00500.x

Serrano, R., \& Huang, H. Y. (2018). Learning vocabulary through assisted repeated reading: How much time should there be between repetitions of the same text? TESOL Quarterly, 52(4), 971-994. DOI: 10.1002/tesq.445

Sobel, H. S., Cepeda, N. J., \& Kapler, I. V. (2011). Spacing effects in real-world classroom vocabulary learning. Applied Cognitive Psychology, 25(5), 763-767. DOI: 10.1002/acp.1747

Tahmasbi, M., \& Farvardin, M. T. (2017). Probing the effects of task types on EFL learners' receptive and productive vocabulary knowledge: The case of involvement load hypothesis. SAGE Open, 7(3). DOI: 10.1177/2158244017730596

Toppino, T. C., \& Gerbier, E. (2014). About practice: Repetition, spacing, and abstraction. In B.H. Ross (Ed.), The psychology of learning and motivation: The psychology of learning and motivation. San Diego, CA: Elsevier Academic Press.

Ullman, M. T., \& Lovelett, J. T. (2018). Implications of the declarative/procedural model for improving second language learning: The role of memory enhancement techniques. Second Language Research, 34(1), 39-65. DOI: 10.1177/0267658316675195

Webb, S. (2005). Receptive and productive vocabulary learning: The effects of reading and writing on word knowledge. Studies in Second Language Acquisition, 27(1), 33-52. DOI: $10.1017 / \mathrm{S} 0272263105050023$

Webb, S. (2008). The effects of context on incidental vocabulary learning. Reading in a Foreign Language, 20, 232-245. Retrieved from https://files.eric.ed.gov/fulltext/EJ815123.pdf 